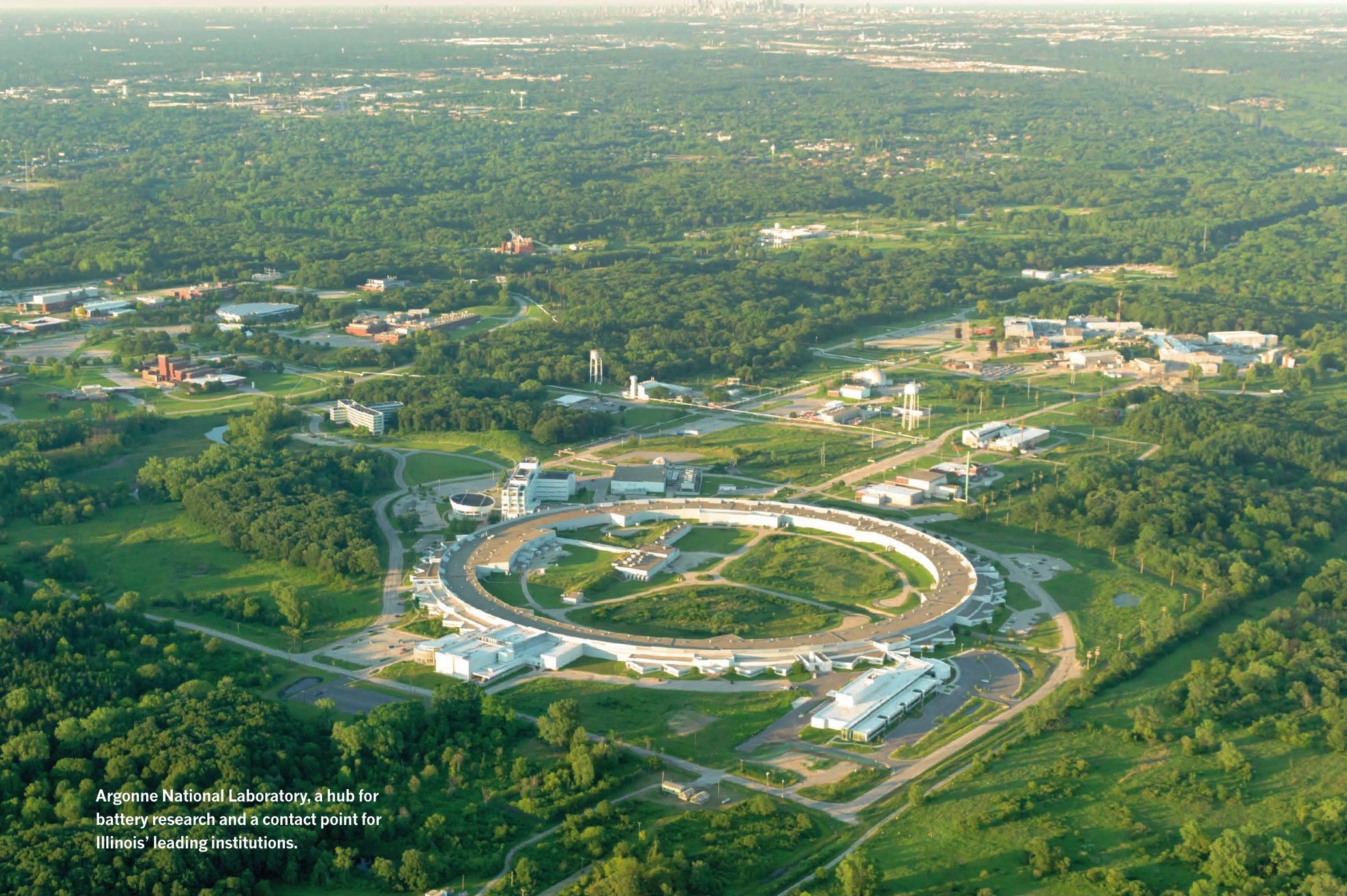

\title{
A STATE OF SUBSTANCE
}

Key investments in people and infrastructure have helped Illinois become a major player in chemistry.

\section{BY CASSANDRA WILLYARD}

$\mathrm{I}$ llinois has become a hotbed of research in the science of matter and its elementary substances. In the index, the state ranks fourth in the United States for its chemistry research output, with a weighted fractional count (WFC) of 360. Almost half the contribution to authorship in the index from researchers in Illinois is in chemistry

Four institutions produce the lion's share of these papers: Northwestern University, University of Illinois at Urbana-Champaign, Argonne National Laboratory, and The University of Chicago.
These institutions have a long history of chemistry excellence. In the wake of World War I, as supplies of organic chemicals dwindled from manufacturers in Germany, Urbana-Champaign launched an operation to synthesize them in the US. The move attracted high-profile chemists like Roger Adams, who worked out the composition of substances such as complex vegetable oils and plant alkaloids. In 1955, chemists at Argonne co-discovered two new elements, einsteinium and fermium.

In the past decade, despite recession, these four institutions have fuelled the state's chemistry research output by pouring money into major infrastructure projects and people.

In the mid-1990s, Northwestern University hired a new leader, Henry Bienen, who developed ambitious plans to expand the university's research capabilities. Chad Mirkin, a chemist who had joined Northwestern in 1991, suggested to Bienen that the university build a centre dedicated to research on the rapidly emerging field of nanotechnology. Mirkin knew that Northwestern could find a niche in a less established field.

Bienen backed the idea. The International Institute of Nanotechnology (IIN) launched in 2000, the same year President Bill Clinton announced the National Nanotechnology 


\section{CHEMISTRY BONDS}

In 2016 , the top 10 chemistry collaborative relationships in the United States in the Nature Index were between institutions in the same state. Collaboration score (CS) sums the contribution from papers with authors from both partnering institutions. Institutions in Illinois contributed to four of the top partnerships.
The University of California, Berkeley (CS: 63.7) contributes to a larger proportion of the authorship in papers it collaborates on with Lawrence Berkeley National Laboratory (CS: 42.9). Total CS is 106.6.
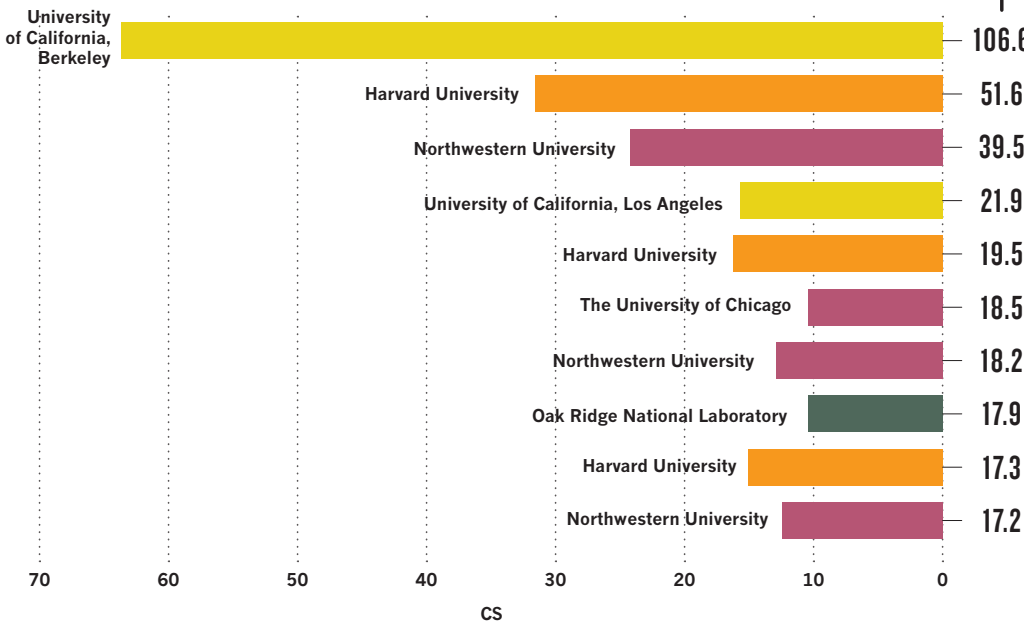

17.2
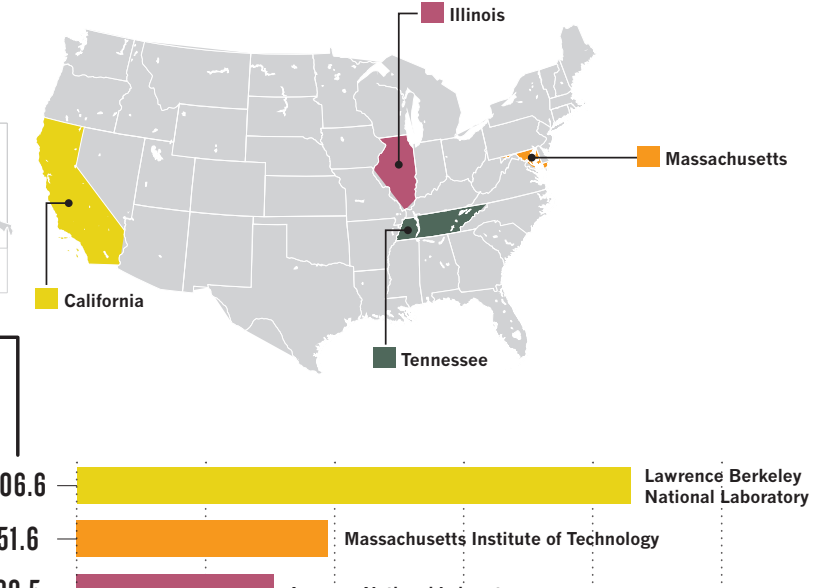

Lawrence Berkeley



1.9 University of California, Santa Barbara

$19.5-$ Boston Úniversity

18.5 Argonne National Laboratory

$8.2-T$ The University of Chicago

17.9 The University of Tennessee at Knoxville

17.3 - Tufts University

University of Illinois at Urbana-Champaign

10

20

30

40

50
Initiative - a US\$497-million, multi-agency project to boost nanoscale science. The IIN's US\$30 million-plus home was opened in 2002.

The IIN and other centres have helped Northwestern attract top-tier researchers, Mirkin says. In 2007, the university recruited superstar chemist Fraser Stoddart, whose work building molecular rings that can move along an axle helped pave the way for nanoscale machines. Stoddart won the Nobel Prize in Chemistry in 2016.

Mirkin has also raised the university's research standing with the discovery of an entirely new way of detecting DNA and other molecules using gold nanoparticles. Today, he is one of the most cited chemists in the world.

Building facilities and recruiting talent requires serious money, which Northwestern had access to. In the late-1980s, chemist Richard Silverman discovered the key ingredient in what eventually became a blockbuster drug for treating nerve pain and epilepsy - pregabalin (marketed by Pfizer as Lyrica).

Most of the funds from the sale of the drug went into Northwestern's already healthy endowment, but quarterly payments from Pfizer helped the university weather the worst of the 2008 economic downturn, which halted building plans in other top-tier universities.

Annual endowment payouts and drug royalties were spent on hiring chemistry faculty and subsidizing new construction, including the Integrated Molecular Structure Education and Research Center, a chemical analysis laboratory. "Lyrica brought in more than a billion dollars to the university at a time when US markets were imploding. So we were in a strong position to keep building," Mirkin says.

Thirty kilometres south, the University of Chicago, has also expanded its chemistry capabilities. In 2009, workers finished a US\$49 million overhaul of the Searle Chemistry Laboratory building.

When construction costs fell and interest rates plummeted after the housing bubble burst, its president, Robert Zimmer, seized the opportunity to further expand. "Many institutions were concerned with financial risk, as of course were we," says Zimmer.

"But, we determined the greater risk was to take a less programmatically ambitious path that could reduce the university's eminence in the long term."

\section{HIGH-ENERGY RING}

In 2011, the university broke ground on the William Eckhardt Research Center, a US\$215 million facility that houses the Pritzker Nanofabrication Facility and the Institute for Molecular Engineering, a joint venture with Argonne. Over the past eight years, the university's chemistry department has hired 15 new faculty, and an additional three chemists and five chemical engineers have joined the Institute for Molecular Engineering.

At the University of Illinois at UrbanaChampaign, the focus has been on nurturing and retaining top-tier faculty. "We grow a lot of faculty from junior faculty level," says chemistry department head, Martin Gruebele.

A contact point for the three universities is the Argonne National Laboratory, which has a synchrotron producing powerful X-rays chemists use to determine the molecular structure of materials.

Researchers at Argonne, Northwestern, The University of Chicago and the University of Illinois at Chicago have recently developed a soft, electrically conductive material made of silicon nanowires that can be injected into the body and degrade naturally. They used the material to optically stimulate nerve cells on a dish, showing its potential for engineering artificial organs. Their research was published in Nature Materials in June 2016.

Argonne is also a hub for battery research. In 2012 the US Department of Energy awarded the lab US $\$ 120$ million over five years to create the Joint Center for Energy Storage Research. The centre connects scientists and engineers from industry, five national laboratories and 10 universities, including Northwestern, UrbanaChampaign, University of Illinois at Chicago and The University of Chicago, which manages and operates Argonne.

Illinois has imported an enormous amount of talent in the past decade, and continues to do so, says Matthew Tirrell, chief research officer for Argonne National Laboratory and director of the Institute for Molecular Engineering. "They're coming because this is the place to do chemical and materials sciences." 